\title{
¿POR QUÉ SURGE EL ESTADO? UNA METODOLOGÍA HOLÍSTICA PARA ENTENDER EL ORIGEN, LA FUNCIÓN Y LOS RETOS DEL PODER PÚBLICO ${ }^{1}$
}

\author{
LUIS I. GORDILLO PÉREZ \\ Universidad de Deusto
}

\begin{abstract}
RESUMEN: el término «Estado» suele emplearse para refirse a un fenómeno político que surgió en Europa a partir del hundimiento del feudalismo con las características fundamentales de territorialidad, centralización, soberanía, diferenciación e institucionalización. Este concepto da lugar a limitaciones, que son consecuencia de la aplicación de una metodología que resulta incompleta para una comprensión integral del Estado, ya que no permite diferenciar, dentro de los llamados Estados, los diversos tipos existentes y las consecuencias políticas y sociales que se derivan de cada uno de estos tipos. Este trabajo defiende el uso de la metodología empleada por Pierre Birnbaum para analizar el Estado en tanto que hecho histórico y social que supone una creación a partir de prácticas sociales propias de un tiempo y un espacio concretos, en relación con una cultura concreta y a lo largo de una determinada trayectoria histórica. Para ello, se expone, en primer lugar, la teoría sociológica-histórica sobre el origen del Estado con la presentación de su metodología y el análisis de la relación del capitalismo, la estructura social y la cultura con el Estado (apartados 2 y 3); en segundo lugar, este trabajo se centra en las ventajas de la metodología propuesta por Birnbaum para analizar el Estado en tanto que creación original, destacando la división Estado fuerte-Estado débil que propone el autor (apartados 4 y 5); y, por ultimo, plantea los retos a los que se enfrenta el Estado en la actualidad (apartados 6 y 7 ).

PALABRAS CLAVE: Teoría del Estado, Birnbaum, Estados fuertes, sociología jurídica, capitalismo.
\end{abstract}

\section{The emergence of the State. A holistic approach to understand the origin, the role and challenges of public power}

ABSTRACT: the term "State" is often used to identify a political phenomenon that emerged in Europe since the collapse of feudalism with the fundamental characteristics of territoriality, centralization, sovereignty, differentiation and institutionalization. This concept leads to limitations that result from the application of a methodology that is incomplete for a comprehensive understanding of the State, as it does not differentiate within the so-called States, the various existing types and political and social consequences derived from each of these types. This paper advocates the use of the methodology used by Pierre Birnbaum to analyze the State as a historical fact and social which is a creation from own social practices of a time and a specific space, in relation to a particular culture and with a particular historical trajectory. To this end, this article deals, first, with the sociological-historical theory on the origin of the State along with the presentation of their methodology and analysis of the relationship of capitalism, social structure and culture with the State (paragraphs 2 and 3) ; secondly, this work

1 Este trabajo se enmarca en una línea de investigación sobre la teoría del Estado y los trabajos de P. Birnbaum realizada conjuntamente con el Profesor Ignacio M. Beobide y es producto de las actividades de los grupos de investigación IT607-13 e IT997-16 (Gobierno Vasco) así como del proyecto DER2013-48327-C3-2-R (MINECO). El autor agradece en particular las críticas, correcciones y comentarios de Patxi Lanceros, Ricardo Pinilla, Javier Martínez Contreras, Demetrio Velasco y de todos los participantes en la Jornada Repensar el Estado y el Poder Público: una perspectiva diacrónica, Universidad de Deusto, Bilbao, 3-4 marzo 2015 (donde se presentó un primer borrador de este trabajo). 
focuses on the advantages of the methodology proposed by Birnbaum to analyze the State while original creation, highlighting the division Strong State / Weak State proposed by the author (4 and 5); and, finally, it raises the challenges facing the State today (paragraphs 6 and 7).

KEY WORDS: state theory, birnbaum, strong states, legal sociology, capitalism.

\section{INTRODUCCIÓN}

Casi todos los estudiosos del Estado, ya sean historiadores, juristas, politólogos, filósofos o sociólogos, utilizan el término «Estado» para referirse a un fenómeno político que surgió en Europa a partir del hundimiento del feudalismo con las características fundamentales de territorialidad, centralización, soberanía, diferenciación e institucionalización y que supuso la separación o la salida de lo político del terreno social y la conversión del individuo en un ciudadano, cuya relación de pertenencia fundamental será con el Estado al margen de cualquier característica particular².

Esta categoría o concepto unívoco de «Estado» da lugar a limitaciones, que son consecuencia de la aplicación de una metodología que resulta incompleta para una comprensión integral del Estado, ya que no permite diferenciar, dentro de los llamados Estados, los diversos tipos existentes y las consecuencias políticas y sociales que se derivan de cada uno de estos tipos. En este contexto, merece la pena fijarse en los estudios de Pierre Birnbaum, que desde un enfoque holístico, que combina el método propio de la solociología histórica sin olvidar la ciencia política y la propia filosofía, propone un enfoque según el cual el Estado es un hecho histórico y social que necesita ser analizado como una creación a partir de prácticas sociales propias de un tiempo y un espacio concretos, en relación con una cultura, también, concreta y a lo largo de una determinada «trayectoria» histórica ${ }^{3}$.

Este artículo expone, en primer lugar, la teoría sociológica-histórica sobre el origen del Estado con la presentación de su metodología y el análisis de la relación del capitalismo, la estructura social y la cultura con el Estado (apartados 2 y 3 ); en segundo lugar, este trabajo se centra en las ventajas de la metodología propuesta por BIRNBAUM para analizar el Estado en tanto que creación original, destacando la división Estado fuerte-Estado débil que propone el autor (apartados 4 y 5); y, por ultimo, plantea los retos a los que se enfrenta el Estado en la actualidad (apartados 6 y 7 ).

2 Así, por ejemplo, vide Burdeau, G., Traité de Science Politique, Tome IV: Le statut de pouvoir dans l'État, LGDJ, Paris, 1969, pp. 1-3; BurdeAu, G., L'Etat, Editions du Seuil, Paris, 1970, pp. 13-17 o Kelsen, H., Compendio de teoría general del Estado, Editorial Blume, Barcelona, 1979 (traducción de Luis Recasens Siches y Justino de Azcárate Flórez), pp. 125-126.

3 En realidad, fue M. Weber quien ofreció el método para analizar el sistema político estatal como un "individuo histórico», obligando así a este enfoque omnicomprensivo u holístico, vide Weber, M., Economía y Sociedad, FCE, México, 1944 (4a reimpresión de la primera edición de 1979), pp. 12-18. 


\section{LAS CARENCIAS DE LAS TEORÍAS CLÁSICAS SOBRE EL ORIGEN DEL ESTADO}

Partimos de la tesis de Badie/Birbaum sobre el origen del Estado: el Estado no es el producto inevitable del desarrollo político y social, sino un fenómeno único, una creación desarrollada dentro de un contexto geográfico e histórico específico ${ }^{4}$.

Sin embargo, existen distintas teorías justificativas del origen del Estado, cada una de ellas enfoca la cuestión desde un punto de vista distinto. A los efectos de este trabajo, merece la pena revisar las que han servido de inspiración a P. Birnbaum, es decir, las construcciones de MarX, Durkheim, Weber ${ }^{5}$.

\subsection{La explicación económica o economicista de Marx}

La interpretación de Karl MARX es la llamada «economicista», "teoría del reflejo» o "materialista». Según esta construcción, los cambios políticos sólo siguen a los cambios económicos. Desde esta perspectiva, el Estado como forma política que sustituye a la poliarquía medieval surgió cuando el capitalismo sustituyó a la economía agraria medieval, basada en los pactos de vasallaje y en la poliarquía. Así, el capitalismo acabó con la poliarquía medieval y motivó la creación del Estado como forma política que inaugura la Edad Moderna. En este sentido, este esquema obedecería a la interpretación histórica que asigna a cada modo de producción una forma de organización política. Así, a los modos de producción esclavista le correspondería el sistema propio de la polis griega; a los modelos de servidumbre medieval, la poliarquía; y al capitalismo, el Estado $^{6}$. No es éste el lugar para realizar una crítica exhaustiva de la concepción

4 Esta tesis se defiende en Badie, B.; Birbaum, P., Sociologie de l'État, Grasset, Paris, 2e ed., 1982, reimp. 2004, pp. 219-222. Esta posición también es mayoritaria en la doctrina italiana (vide Pizzorusso, A., Lecciones de Derecho Constitucional, CEPC, Madrid, 1984, vol. I, pp. 4-5).

5 Para un análisis previo de la construcción propia de Birnbaum, vide Badie, B.; Déloye, Y. (Dirs.), Le temps de l'État. Mélanges en l'honneur de Pierre Birnbaum, Fayard, Paris, 2007, Beobide Ezpeleta, I. M.; Gordillo Pérez, L. I., La naturaleza del Estado. Origen, tipología y lógica de actuación política y social, Tecnos, Madrid, 2012 y Beobide EzPeleta, I. M.; Gordillo Pérez, L. I., «La alternativa al funcionalismo y al marxismo: la sociología del Estado de Birnbaum», Revista de Estudios Políticos, núm. 156, 2012, pp. 167-207

6 Las consideraciones fundamentales a este respecto, las realiza el autor en su obra MarX, K., Das Kapital. Kritik der politischen Ökonomie, que se iría publicando entre 1867 y 1894 (con distintas versiones en castellano, entre otras, MARX, C., El Capital, Akal, Madrid, 1977, traducción de Vicente Romano García) y algo más sucintamente en su Crítica al programa de Gotha (redactado en 1875 y publicado póstumamente por F. Engels en 1891, con el título original Die Kritik des Gothaer Programms, disponible en <http://www.mlwerke.de/me/ me19/me19_013.htm>, última consulta 12 septiembre 2016 y disponible en español, entre otras, en la siguiente recopilación: MARX, K., Textos selectos y manuscritos de París. Manifiesto del Partido Comunista. Crítica del Programa de Gotha, Gredos, Madrid, 2012, traducción y notas de Jacobo Muñoz). También hay que tener en cuenta la interpretación realizada en ENGELs, F., Der Ursprung der Familie, des Privateigenthums und des Staats. Im Anschluss an Lewis 
del Estado en MARX. Baste recordar que su enfoque y preocupación netamente económicos hizo que no dedicara demasiada atención a la construcción de una teoría general (y autónoma) del Estado7 .

BaDIE/BIRBAUm discrepan con MarX porque según la concepción de éstos no es la aparición y el posterior desarrollo del capitalismo lo que conduce al Estado, sino sus propias limitaciones. En este sentido, el Estado surgiría como la única solución política capaz de romper con las contradicciones que el capitalismo había puesto de manifiesto pero que éste por su propio desarrollo era incapaz de superar. Con la aparición del capitalismo queda patente que aunque son los nobles los que formalmente tienen el poder político, es la clase social burguesa la que ostenta cada vez de forma más hegemónica el poder económico y crece su peso en la toma de decisiones políticas pero sin poder participar directamente en la toma de las mismas. Ante esta situación, el desarrollo del capitalismo provoca un choque cada vez más directo y contundente entre las posturas inmovilistas de la nobleza medieval y las demandas de cambio en la forma de organización política protagonizadas por la burguesía. Fruto de esta convulsión histórica, surgiría el Estado como solución para superar esas contradicciones ${ }^{8}$.

\subsection{El enfoque sociológico de Durkheim}

En su tesis doctoral, Emile DuRKheIm sostenía que el origen del Estado radica en la división social del trabajo9. Hay división del trabajo cuando una sociedad alcanza un grado de desarrollo tal que se produce un desdoblamiento de las tareas productivas. Así, se produciría una diferenciación ocupacional en la que funciones y tareas productivas quedan asignadas a personas distintas ${ }^{10}$.

H. Morgan's Forschungen, publicada en 1884 (versión en alemán disponible en <http://www. mlwerke.de/me/me21/me21_025.htm>, última consulta: 12 septiembre 2016 y traducida al español, entre otras versiones, como ENGELs, F., Origen de la familia, de la propiedad privada y del Estado, La España moderna, Madrid, 1891?, no figura el nombre del traductor, disponible en <http://fama2.us.es/fde/ocr/2008/origen_De_La_Familia_La_Propiedad_Privada_Y_El_Estado.pdf >, última consulta 12 septiembre 2016). Vide, igualmente, Martínez MarzoA, F., La filosofía de 'El capital', Taurus, Madrid, 1982.

7 La literatura sobre esta cuestión es inabarcable, para una muestra, vide BLACKBURN, R., «Marxism: theory of proletarian revolution», New Left Review, Vol. I/97, May-June 1976, pp. 3-35; Poulantzas, N., L'État, le pouvoir, le socialisme, Paris, PUF, 1978; Althusser, L; Balibar, E.; Establet, R.; Macherey, P.; Rancière, J., Lire le Capital, Maspero, Paris, 1965 (2 vols.).

8 Badie, B., Birbaum, P., Sociologie de l'État, Grasset, Paris, 2e ed., 1982 (reimp. 2004), pp. 15-27.

9 Su «tesis de Estado» sería publicada como De la division du travail social, Félix Alcan, Paris 1893 (reimprensión PUF, Paris, 2007). Existe una versión en español, publicada como Durkheim, E., De la División del Trabajo Social, Akal, 4ª ed., 2001 (traducción de Carlos García Posada).

10 Para un análisis crítico de esta teoría, vide Merton, R. K., «Durkheim's Division of Labor in Society», American Journal of Sociology, Vol. 40/3, 1934, pp. 319-328 y, más recientemente, Monereo Pérez, J. L., «El pensamiento político-jurídico de Durkheim: solidaridad, 
De este modo, la evolución de las sociedades humanas crea un tipo de cohesión llamado solidaridad orgánica (en contraposición a la solidaridad mecánica, propia de las sociedades primitivas) que se produce cuando las sociedades llegan a un nivel de desarrollo tal que cada individuo se especializa en alguna tarea o función social, concentrando parte de los recursos o conocimientos de la misma. Se produce, pues, un tránsito de la familia autosuficiente que realizaba todas las funciones y tareas necesarias para la vida de un ser humano (procurar alimentos, enseres, vestido...) a un modelo en el que se produce una especialización en las distintas tareas productivas y funciones sociales. De la familia autosuficiente y aislada pasamos a la familia moderna en la que los lazos entre los individuos forzosamente se ven incrementados en tanto que se necesitan unos a otros para cubrir sus necesidades. A esta situación la denomina DURKHEIM «solidaridad orgánica» .

El Estado sería, pues, un órgano distinto y autónomo de la sociedad que reviste un carácter funcional para la sociedad moderna. Un Estado utilitario al que correspondería organizar y optimizar esas relaciones que se producen de forma natural en las sociedades modernas. De este modo, la tesis de DuRKHEIM sobre el origen del Estado hace hincapié en que se trata de un fenómeno normal que resulta del progreso mismo de la división social del trabajo ${ }^{11}$. Así pues, frente a la tesis marxista que postula que el Estado es el agente y servidor de la burguesía, DuRKheIm defiende que el Estado es, sin embargo, el instrumento funcional de la sociedad y del individuo modernos.

\subsection{La aproximación política de Weber}

Para estudiar la aparición del Estado, WeBER realiza un análisis histórico de las diferentes concepciones de la autoridad y acaba distinguiendo tres formas principales de dominación legítima (carismática, tradicional y racional). Así, la llamada autoridad carismática dependía de las cualidades excepcionales del líder; la tradicional estaba basada en la costumbre de obedecer a un determinado linaje y la racional fundamentaría su legitimidad en el criterio del Derecho y las normas. Así, explicará la aparición del Estado por el paso de la autoridad carismática y tradicional (propia de la Edad Media) a una autoridad racional. El Estado surgiría, pues, en conexión con los esfuerzos por tratar de sustituir una administración feudal por una centralizada, institucionalizada, organizada con arreglo a Derecho ${ }^{12}$.

anomia y democracia (II)», Revista de derecho constitucional europeo, núm. 10, 2008, pp. 387-434.

${ }_{11}$ En este sentido, vide la explicación y crítica en Badie, B.; Birbaum, P., Sociologie de l'État, op. cit., especialmente, p. 30.

12 La obra de WeBer es casi inabarcable. Entre sus principales trabajos sobre la teoría del Estado, cabe citar Weber, M., Wirtschaft und Gesellschaft, Mohr, Tübingen, 1922 (publicado en inglés como WeBER, M., Economy and Society. An outline of interpretive sociology, University of California Press, Berkeley, 1978, traducción de Günther Roth y Claus Wittich de la cuarta edición en alemán de 1956) y WEBER, M., Die protestantische Ethik und der Geist 
La Tesis de Weber será pues que el paso de una administración patrimonial feudal basada en la autoridad (legitimidad, dominación) tradicional (es decir, legitimidad patrimonial) a una administración burocrática (burocracia) basada en la autoridad legal será el origen y la explicación de la aparición del Estado. El Estado se convierte, por tanto, en una institución distinta de la sociedad $^{13}$. Por Estado, dirá Weber, se entiende aquella empresa política de carácter institucional en la que la estructura administrativa, al hacer cumplir sus normas, reivindica con éxito el monopolio de la fuerza física legítima ${ }^{14}$.

\section{LA SUPERACIÓN DEL MÉTODO SOCIOLÓGICO}

\subsection{La necesidad de incluir el criterio histórico-filosófico}

El enfoque histórico propone la tesis de que el Estado surgió, por primera vez, en algunos países de la Europa occidental, aquellos a los que Gellner sitúa dentro de la primera zona horaria (Inglaterra, Francia, Portugal y España), caracterizados por la unión entre Estado y cultura siglos antes de la aparición del nacionalismo ${ }^{15}$. Razones endógenas, se puede decir, llevaron a la aparición del Estado. Posteriormente, esta nueva forma política fue extendiéndose, poco a poco, a otros países hasta formar los más de 190 Estados existentes en la actualidad. En estos otros casos fueron razones exógenas, entre ellas la eficacia del modelo político Estado o de algunos de sus elementos, las que llevaron a su creación. Los inicios de esta nueva realidad política se dejaron ver a partir de los primeros siglos de la Edad Media, la llamada Alta Edad Media, que abarca los siglos Ix al XI, desde la coronación de Carlomagno como emperador del Sacro Imperio Romano (Romanum gubernans Imperium) en la Navidad del año 800 (799 según otros) hasta la conquista, al asalto, de Jerusalén por los cruzados en 1099.

El tránsito de la poliarquía medieval al moderno Estado es tributario de una serie de hechos o factores históricos que se manifiestan esencialmente en la Baja Edad Media y entre ellos destacan la expansión territorial, la nueva economía, la familia nuclear, la recuperación de las ciudades y el renacimiento

des Kapitalismus, Mohr, Tübingen 1934 (publicado inicialmente en el Archiv für Sozialwissenschaften und Sozialpolitik, Bd. XX/XXI, 1904-1905). Para un estudio de la cuestión, vide CAmic, Сh.;, Gorski, P. S.; TrubeK, D. M., (Eds.), Max Weber's Economy and Society: A Critical Companion, University Press, Stanford, 2005 y Albrow, M., Max Weber's Construction of Social Theory, MacMillan, London, 1990.

13 Vide la versión en español, Weber, M., Economía y Sociedad, op. cit., pp. 1056 y 1060.

14 Para unos estudios recientes en español, vide Monereo Pérez, J. L., Modernidad y capitalismo. Max Weber y los dilemas de la Teoría Política y Jurídica, El Viejo Topo, Barcelona, 2013 y el excelente trabajo de Villacañas Berlanga, L., "Legitimidad y legalidad en Max Weber», Menéndez Alzamora, M. (Ed.), Sobre el Poder, Tecnos, Madrid, 2007, pp. 49-108.

15 Gellner, E., Nacionalismo, Destino, Barcelona, 1998 (traducción de Ferrán Meler), p. 98 . 
comercial, la consolidación interna (institucional y dogmática) y externa de la Iglesia, el redescrubrimiento del Derecho romano, el renacimiento cultural del siglo XII: escuelas y universidades o el ascenso de los reyes ${ }^{16}$.

Las raíces del llamado Estado moderno se encuentran, pues, en la Edad Media y fueron el resultado de las transformaciones tanto ideológicas como institucionales que afectaron al sistema feudal al transformar el concepto de poder y que, en último caso, favorecieron la concentración del poder en la persona del rey situando a la monarquía en el centro de la actividad política. En los dos últimos siglos medievales apareció lo que puede denominarse el espíritu laico, es decir, una actitud que, a través de la observación y al margen de criterios religiosos, trataba de entender la naturaleza y la realidad social. El espíritu laico se aplicó, entre otros campos, a la política y al poder, y el resultado de tal actitud fue el descubrimiento de la necesidad de la reforma política, en primer lugar, y la reforma de la Iglesia, en segundo lugar. La mejora de la eficacia del Reino y de la Iglesia era la obra encomendada a los reyes (o la tarea de los reyes). La separación entre los reyes y la Iglesia ya se había producido cuando comenzó el trabajo teórico de elaboración de una doctrina del poder político liberada del componente sobrenatural. Y el motor del cambio estuvo en la recepción de Aristóteles y en su utilización por parte de Santo Tomás, que asentó la interpretación de lo político como un ámbito pleno de sentido y validez al margen de lo religioso. La culminación de este proceso intelectual está en Maquiavelo que fue el primero en intentar realizar un estudio científico del fenómeno político. Con Maquiavelo desaparece hasta el último resto de lo sobrenatural en su concepción y justificación de lo que por primera vez se llamará Estado ${ }^{17}$.

Al trabajo de estos autores se sumaría el de los juristas. A base de Derecho civil y Derecho romano excluyeron del gobierno de los reinos al Papa y al Emperador y defendieron o bien el poder de los ciudadanos en las ciudades o bien el poder de los reyes en sus reinos. La conclusión del rey como centro único del poder y como poder de origen popular sería la obra final de los historiadores del siglo xv. La potenciación de la monarquía se hizo en dos campos: en primer lugar, frente y contra el Emperador y el Papa y, en segundo lugar, en competencia con los señores feudales (nobleza) y las ciudades. Por lo que respecta a la Iglesia-Papado, el ascenso de los monarcas siguió a la pérdida de poder del Papado ante el fracaso de sus pretensiones teocráticas y las nuevas realidades sociales y económicas. El impulso decisivo a favor de la monarquía vino a través de la burguesía, que aportó no sólo una nueva economía monetaria, sino, también, un sentido de comunidad e interés general que superaba el planteamiento individualista del sistema feudal. El apoyo fundamental vino a través de la institución de las asambleas representativas, donde se puso de manifiesto

16 Para un análisis en profundidad de estos factores, vide Beobide EzPeleta, I. M.; GorDillo Pérez, L. I., La naturaleza del Estado. Origen, tipología y lógica de actuación política y social, op. cit., pp. 19-64.

17 Sobre esta cuestión, vide, in extenso, SABINE, G. H., Historia de la teoría política, FCE, México, $3^{\text {a }}$ ed. en español, ( $5^{\mathrm{a}}$ reimpresión), 2002, pp. 129-280. 
que el rey, además de ser señor de unos vasallos, era la cabeza de una comunidad que, por incluir a todos, daba entrada en las asambleas, inicialmente curias feudales, a los eclesiásticos y a los representantes de las ciudades. Éstos tenían por objetivo la defensa de los intereses de la población urbana, pero su presencia en las asambleas iba a ser de mutuo beneficio para la clase burguesa y para la monarquía. La aportación económica de aquélla se correspondía con el reconocimiento de sus privilegios y libertades. Pero, con el paso del tiempo y coincidiendo con el descenso de la importancia de las asambleas, la presión del monarca a través de sus oficiales iba desequilibrar la situación a favor del rey ${ }^{18}$.

Ahora bien, de manera previa a este fortalecimiento del rey sobre las demás instituciones, la idea de comunidad como base del poder soberano requería alguna forma de conciencia colectiva y algún sentido de identidad, que permitiera la distinción entre un natural y comunitario, por un lado, y el extranjero y extraño, por el otro. A esto respondería el sentido de "nación» (patria, país, lengua, costumbres) que, según Cortázar, estaba extendida por casi todos los Estados al finalizar la Edad Media, nación por la que había que «vivir y morir y con una monarquía» ${ }^{19}$.

Al papel que el sentido de comunidad pudo jugar en la potenciación de la hegemonía de la monarquía se unió el de las guerras de los dos últimos siglos medievales, no sólo por sus efectos en la configuración de los reinos y en el aumento del poder real, sino por su elevado coste, razón que influyó directamente en el desarrollo y justificación de lo que sería el eje del Estado, la centralización del sistema fiscal. Fue aquí donde las ciudades jugaron un papel extraordinario y donde se demostraría la convergencia de intereses entre el rey, que los satisfacía con los impuestos permitidos por él mismo, y las ciudades, que ganaban más libertad para sus órganos de gobierno. Los impuestos justificados, en principio, al amparo de la guerra se harían definitivos.

La forma de administración que aplicó la nueva concepción del poder político fue la centralización, compuesta por profesionales, técnicos formados en las universidades y menos por personalidades nobiliarias o religiosas. Estos profesionales casi llegaron a convertirse en dueños de su oficio, que podían, por tanto, venderlo o transmitirlo a sus herederos. El desarrollo de este sistema se llevó a cabo en conflicto con el sistema feudal (particularidades señoriales), ya que la centralización exigía la presencia de los oficiales del rey en los territorios regionales del reino, donde actuaban los señores. Pero la dependencia

18 Para un estudio en profundidad que desarrolla esta cuestión, vide STOLLEIS, M., «Condere leges et interpretari. Gesetzgebungsmacht und Staatsbildung in der frühen Neuzeit», Zeitschrift für Rechtsgeschichte, Germanistische Abteilung, N. 101, 1984, pp. 89-116 (traducido al español como «Condere leges et interpretari. Poder legislativo y formación del Estado en la Edad Moderna», SтоLleIs, M., La textura histórica de las formas políticas, Marcial Pons, Madrid, 2011, pp. 37-59, traducción de Ignacio Gutiérrez).

19 Para Maravall esta forma de conciencia colectiva y sentido de identidad era propia de un nuevo tipo de comunidad, la "comunidad protonacional» (MARAVALL, J. A., Las comunidades de Castilla, Ed. Revista de Occidente, Madrid,1970, pp. 63-72, especialmente, p. 72). 
económica de los señoríos con respecto a la Hacienda del rey —y los señoríos sin herederos- permitió el control de los señores y la extensión del poder real. La centralización exigió y potenció el control de todo el territorio y de su riqueza, lo que dio lugar a una administración escrita (documentos) capaz de transmitir toda la información necesaria y a un centro administrativo urbano, precedente de las futuras capitales de los reinos europeos ${ }^{20}$. El resultado de este proceso histórico sería la aparición y consiguiente consolidación en Europa de Estados como Francia, España o Inglaterra. Es lo que José Antonio Maravall, refiriéndose, especialmente, al caso de la Historia de España (siglos XV-XVII) llama «la época de la revolución estatal».

Ahora bien, estas aportaciones imprescindibles de la historia son insuficientes, si no se tienen en cuenta otras categorías de análisis y otra metodología, que permitan evitar el error de concluir que el Estado postmedieval fue igual en todos los casos europeos, porque fue fruto de una evolución idéntica. La sociología que propone Birnbaum para analizar el Estado permite superar estas insuficiencias.

\subsection{El enfoque birnbaumiano}

El método que emplea Pierre BIRnBaum en sus estudios sobre la teoría del Estado, que cabría extender a cualquier análisis sobre la esencia del poder público en general, parte de la base de que el Estado es un fenómeno histórico social $^{21}$. La inspiración metodológica de la que parte este autor, a diferencia de sus contemporáneos, se apoya en WEBER, pero, también, en los análisis funcionalistas de Emile Durkheim e, incluso, en determinados trabajos de MARx en los que éste concluye que el Estado despótico llega a hacerse independiente de todas las clases sociales, algo muy distinto de lo que se establece en el materialismo histórico y dialéctico del propio MARX ${ }^{22}$.

Su punto de partida es, precisamente, el análisis crítico del funcionalismo de autores como Parsons o SMELSER con el objetivo de encontrar en él los elementos positivos para una explicación sociológica del origen y funcionamiento del Estado ${ }^{23}$. Las aportaciones neo-funcionalistas son claras en la descripción de algunos rasgos esenciales del Estado y de sus características de funcionamiento, pero la fosilización que hace de sus datos impide ver los efectos de «composición o de innovación» del Estado y lo hace incapaz de crear una

20 García de Cortázar, J. Á., Sesma Muñoz, J. Á., Historia de la Edad Media. Una síntesis interpretativa, Alianza Universidad, Madrid, 1997, pp. 650-678.

21 Esta cuestión ha sido desarrollada in extenso en Beobide EzPeleta, I. M.; Gordillo PÉREz, L. I., «La alternativa al funcionalismo y al marxismo: la sociología del Estado de Birnbaum», op. cit.

22 Vide en este sentido Badie, B.; Birbaum, P., Sociologie de l'État, op. cit., especialmente, pp. 15-27 y el apartado 2 de este trabajo.

23 Parsons, T., The Social System, 2nd ed., Routledge, London, 2005 (original publicado en 1951, segunda edición de 1991); CHAzEL, F., La théorie analytique de la société dans l'auvre de Talcott Parsons, Paris, Mouton, 1974; Smelser, N. J., The Sociology of Economic Life, Englewood Cliffs, Prentice-Hall (NJ), 1963. 
teoría general explicativa ${ }^{24}$. En este sentido, BIRNBAum hace especial hincapié en la necesidad de reconocer al Estado como fenómeno diferenciado y negarle este nombre a todo poder que no haya alcanzado ese grado de desarrollo ${ }^{25}$.

Las teorías neofuncionalistas, por su parte, recurren al concepto de diferenciación como principio fundamental del cambio social, de forma que el Estado emergería como un producto más de un evolucionismo social en lugar de aparecer como un hecho histórico. Así, el Estado sería el resultado «inmanente, endógeno, uniforme, finalista y continuo» del crecimiento social ${ }^{26}$. Esto contradice las aportaciones de los historiadores, para quienes el feudalismo, los cambios sociales y económicos, el Derecho romano, las migraciones, el sistema económico internacional y la presión militar exterior fueron factores que estuvieron en el nacimiento de los Estados. Es decir, un proceso particular prima sobre un proceso universal. La idea de una diferenciación universalmente racionalizadora y reguladora de tensiones sociales, defendida por el neofuncionalismo, se contradice con los hechos y con los datos históricos. La conclusión sería que el neofuncionalismo exagera la capacidad de explicación de la categoría de la diferenciación al construirla como una variable independiente al margen de los datos sociales reales, como podían ser, además de los nuevos fenómenos sociales, la tradición, las formas antiguas de poder o los mecanismos devolutivos. Según esto, el análisis del origen del Estado debe tener en cuenta no sólo los nuevos elementos sociales, fruto de la diferenciación o de la industrialización, sino, también, las estructuras anteriores de poder, su rigidez y su crisis. Esto permite adelantar que el Estado no surgió tanto para confirmar lo nuevo, la diferenciación de la sociedad, cuanto para hacer frente a la involución de determinadas instancias y estructuras, que no habían sabido adaptarse ${ }^{27}$.

Así, pues, la creación del Estado no dependía únicamente de la diferenciación-no diferenciación, sino de un nuevo proceso de cambio social en el que las estructuras sociales evolucionan, se dividen y se especializan para cumplir funciones cada vez más precisas, pero también mutan uniéndose y añadiendo nuevas estructuras para cumplir funciones que no existían previamente ${ }^{28}$. Esto ocurrió con la creación del Estado, que, si bien era un sistema más diferenciado que el anterior sistema político, también era fruto de la unión de territorios y poderes dispersos y de la creación de nuevas instituciones capaces de desarrollar funciones nuevas. El método de análisis de BIRnBAum añadiría las tesis

24 Badie, B.; Birnbaum, P., "Sociologie de l'Etat revisitée», Revue Internationale de Sciences Sociales, n. 140, 1994, p. 192 (189-203).

25 Birnbaum, P., «La fin de l’État ?», Revue Francaise de Science Politique, Vol. 35/6, 1985, p. 982 (981-998).

26 Badie, B.; Birbaum, P., Sociologie de l'État, op. cit.,p. 87.

27 Esta es la tesis fundamental de los trabajos de Pierre Birnbaum sobre la teoría del Estado.

${ }_{28}$ Etzioni, A., "The Epigenesis of Political Communities at the International Level», American Journal of Sociology, Vol. LXVIII/4 4, 1963, pp. 407-421. 
propias de la sociología histórica, es decir, que el Estado unificado siguió a un sistema feudal y señorial dividido, donde las rivalidades y enfrentamientos entre señores se resolvieron mediante la imposición del monopolio político de uno de ellos, y que el Estado del renacimiento provino fundamentalmente de la coalición de señores feudales y de intereses particulares. Siendo esto así, el Estado no es, en principio, neutro y totalmente autónomo, sino que dependería en cierto modo de fuerzas sociales y de especialistas (políticos y administradores) que controlan y dirigen las nuevas estructuras y funciones. La «clase política» se constituiría, así, en la pantalla entre la universalidad del Estado y la realidad de su funcionamiento ${ }^{29}$.

La construcción del Estado sirvió para compensar los efectos de la división del trabajo y para realizar los objetivos de los grupos sociales subyacentes al Estado. Esto quiere decir que el Estado fue una nueva creación de poder (no una mera cesión de los poderes anteriores) y que esta creación de poder dependió en cierta medida de las circunstancias históricas ${ }^{30}$. La distinción entre Estado en sentido estricto y sistema político centralizado (una forma más suave de Estado), conceptos utilizados para referirse a los dos modelos políticos surgidos a partir de la Edad Media en Europa, dependía de la intensidad de la centralización política y de las nuevas funciones a realizar ${ }^{31}$. Así pues, la tesis funcionalista de que el Estado no era más que la reorganización y redistribución de las estructuras de dominación ante la división del trabajo social se mostraría insuficiente ${ }^{32}$. El neofuncionalismo tampoco ofrecería una respuesta completa al afirmar que el Estado-nación fue un instrumento funcional sustituto de las solidaridades medievales y creador de un nuevo consenso en medio de la nueva división social del trabajo. Se trata de una visión organicista, que no se corresponde con la realidad. El Estado, por el contrario, no sólo es una fuente autónoma de poder, sino también un motivo de lucha política y no, precisamente, de reconciliación de intereses opuestos. Más bien, tiende a agudizar los conflictos y él mismo se convierte en elemento de confrontación, lo que según el organicismo, convertiría al Estado en disfuncional. Por tanto, no se podría sostener la idea de que el Estado confirmaba una perfecta diferenciación entre

29 Vide el caso de la «fallida» institucionalización de Prusia y el papel de los Junkers alemanes en Badie, B.; Birbaum, P., Sociologie de l'État, op. cit., pp. 188-194 (traducido al español en Beobide EzPeleta, I. M.; Gordillo Pérez, L. I., La naturaleza del Estado. Origen, tipología y lógica de actuación política y social, op. cit., pp. 162-167).

30 Para una panorámica de las recientes aportaciones sobre la teoría del poder, vide Stewart, A., Theories of power and domination. The Politics of Empowerment in Late Modernity, Sage, London, 2001, especialmente, pp. 11-34 y MenÉndez Alzamora, M., «El poder. Las perspectivas contemporáneas», Menéndez Alzamora, M. (Ed.), Sobre el poder, op. cit., pp. 141-207.

31 Vide el interesante análisis realizado en Badie, B.; Birbaum, P., Sociologie de l'État, op. cit., pp. 196-217.

${ }_{32}$ Vide Durkheim, E., De la División del Trabajo Social, op. cit., especialmente, pp. 57-270. 
lo público y lo privado y entre lo político y lo social ${ }^{33}$. Es la diferenciación, una vez más la que se pone en dificultades, porque no aparece una sociedad espontáneamente consensuada de acuerdo con el principio de disociación defendido por el funcionalismo, sino una sociedad que tiene por uno de sus ejes fundamentales el conflicto de intereses. Y no probaría nada en contrario, es decir, no demuestra la neutralidad del sistema político estatal, el hecho de que el Estado de bienestar actúe como distribuidor y árbitro entre los grupos sociales, ya que el Estado puede seguir actuando de forma selectiva, interviniendo únicamente en lo necesario para el mantenimiento del orden social sin poner en cuestión lo esencial de tal orden y, en concreto, la propiedad privada. En definitiva, la sociología del Estado es inseparable de la sociedad y de sus estructuras, de manera que la diferenciación no puede explicar nada a menos que se contextualice históricamente y se asocie a problemáticas que el funcionalismo se empeña en ignorar, y ésta es una de las principales advertencias metodológicas que realiza BIRNBAUM $^{34}$.

$\mathrm{Al}$ igual que marxismo o la antropología clásica, el neofuncionalismo cometería el error de defender que el Estado en sentido estricto es un modelo universal, que ha de existir en todas partes como instrumento de racionalización de todos los sistemas sociales tradicionales al margen de las particularidades culturales de cada lugar. No se piensa que la racionalización de la tradición puede hacerse de maneras distintas a como se hizo, en su momento, en las sociedades europeas. Precisamente, fue la variable cultural —entendiendo por cultura el conjunto de estructuras de significación por las que los hombres dan forma a su experiencia ${ }^{35}$ - la que jugó un papel importante en la explicación del origen del Estado y puede, en la actualidad, ayudar a encontrar respuestas al fracaso del Estado en países culturalmente distintos ${ }^{36}$. No hay, pues, un modelo universal de Estado, efecto de la división social del trabajo, porque no es la diferenciación la que explica el Estado, sino un tipo determinado de diferenciación, propio del contexto histórico social de la Europa occidental postfeudal. Los cambios políticos no son otra cosa que la forma original y específica de resolver el encuentro de la tradición social con las novedades económicas, sociales y políticas. El cambio político va unido a la continuidad de ciertos elementos sociales, diferentes según las culturas y, por ello, creadores de formas distintas de centralización política. De este modo, las notas que el funcionalismo atribuye al Estado nacional pueden considerarse que se deben, si no en su totalidad, sí, al menos, parcialmente, a la cultura occidental europea. Características como la diferenciación, la autonomía, la universalización o la institucionalización del sistema político estatal no se deben a unas condiciones universales, ni forman

33 Sobre el neofuncionalismo, vide inter alia, AleXANDER, J. C., Neofunctionalism and After, Basil Blackwell, New York, 1998.

34 Badie, B.; Birbaum, P., Sociologie de l'État, op. cit., pp. 143-153.

35 Geertz, C., The Interpretation of Cultures, Basic Books Classics, New York, 1973.

36 Vide Badie, B.; Birbaum, P., Sociologie de l'État, op. cit., pp. 160-168, donde los autores hablan de la aplicación del modelo a los países del tercer mundo. 
una categoría universalizable, sino que integran una categoría concreta europea, que se debe a rasgos específicos como fueron la feudalidad, la separación de política y religión, la descentralización de los señoríos, la burocratización o la organización constitucional ${ }^{37}$.

El enfoque de BiRnBAum ha insistido en destacar los efectos negativos y las deficiencias metodológicas del funcionalismo discutiéndole todas sus interpretaciones clásicas sobre el Estado como son: la tesis de que el Estado respondía a las necesidades de una naciente economía mercantil, cuando su génesis nos sitúa en una economía rural previa a la aparición del capitalismo, o que el Estado obedecía a las necesidades de la aristocracia liberada del feudalismo sin tener en cuenta que el Estado atendió, en primer lugar, a sus propias necesidades a expensas de la clase dominante, o que era el instrumento que regulaba una sociedad civil afectada por el conflicto de clases o el mantenedor del orden social rural, «iniciador de un neo-mercantilismo que dificultaba los intercambios, generador de una burocracia fuente de nuevos bloqueos ${ }^{38}$.

\section{LOS EJES DE LA METODOLOGÍA BIRNBAUMIANA}

La explicación del origen del Estado requiere por tanto de un enfoque holístico u omnicomprensivo que tenga en cuenta los elementos económicos, sociales y políticos, así como un análisis de la cultura europea que va unida a tales elementos. El efecto de este segundo análisis puede ser discriminante o decisivo a la hora de plantear en qué medida el Estado es aplicable en los países del tercer mundo. Por consiguiente, el capitalismo, la estructura social y la cultura son tres factores que hay que tener en cuenta para explicar causalmente el fenómeno de la creación del Estado, que no deja de ser una forma específica de centralización política ${ }^{39}$. Así pues, se hace necesario revisar críticamente los postulados de ciertos autores que al referirse a los factores o circunstancias favorables o contrarios a la centralización, no distinguen los diversos tipos de centralización y se refieren simplemente a una centralización general y unívoca de los Estados europeos ${ }^{40}$.

37 Para una panorámica histórico-constitucional de la especificidad europea, vide STOLLEIs, M., «Die Idee des souveränen States», Mussgnug, R. (Hrsg.), Entstehen und Wandel verfassungsrechtlichen Denkens, Der Staat, Suplemento 11, Duncker \& Humblot, Berlin, pp. 63-85 (traducido al español como «La idea del Estado soberano», STolLeis, M., La textura histórica de las formas políticas, Marcial Pons, Madrid, 2011, pp. 13-35, traducción de Ignacio Gutiérrez).

38 Badie, B.; Birnbaum, P., «Sociologie de l'Etat revisitée», Revue Internationale de Sciences Sociales, n. 140, 1994, p. 192 (189-203).

39 Badie, B.; Birnbaum, P., Sociologie de l'État, op. cit., pp. 87-108.

40 Schulze, H., Estado y Nación en Europa, Crítica, Barcelona, 1997 (traducción de Ernest Marcos), pp. 38-39. 


\subsection{La variable económica: 'Estados fuertes' y 'Estados débiles'}

La centralización política no ha sido una característica exclusiva del proceso de modernización europeo o de la época contemporánea. La novedad frente al pasado consiste en que en la actualidad todas las sociedades modernas necesitan un centro de coordinación ante la división actual del trabajo. Pero no cabe hablar de centralización, sino de tipos de centralización, cuya diversidad depende de las situaciones concretas y de las diferentes culturas. El Estado no es más que un modelo de centralización, producto «de una historia, la de la Europa occidental, y de una época, la del Renacimiento» ${ }^{41}$, aunque las grandes transformaciones del Renacimiento tuvieron lugar cuando ya existía el Estado. Ahora bien, el Estado no puede ser considerado como la solución universal de cualquier crisis.

Los dos conceptos claves que aporta BIRNBAum para referirse a los sistemas políticos, nacidos a partir de la Edad Media, son el de Estado débil — sistema político centralizado - y el de Estado fuerte (Estado en sentido estricto) - sistema político centralizado altamente burocratizado y que ejercer el poder de manera intensa o "autoritario», concepto que emplea el autor pero que no es contrario al elemento democrático-. El primero, simplemente sistema político centralizado, está estrechamente unido con la extensión de la división social del trabajo ${ }^{42}$. Allí donde las estructuras comunitarias tradicionales desaparecieron a través de la lenta construcción de una economía mercantil, fue donde surgieron nuevas estructuras políticas de coordinación, una élite política especializada, dependencia creciente entre el campo y la ciudad y, en definitiva, la autonomización de un espacio político diferenciado. Éste sería el caso de los Países Bajos, centro del nuevo sistema económico, libre de estructuras autoritarias y dirigido de una manera 'constitucional' y, también, de Inglaterra, que, a pesar del fortalecimiento del ejecutivo y de los funcionarios centrales, retuvo estructuras centralizadas débiles y poco intervencionistas. Donde, por el contrario, la división social del trabajo fue débil, el desarrollo económico tardío y brutal y la resistencia al cambio de las estructuras sociales comunitarias fuerte, allí se produjo una oposición frontal a la centralización. Las consecuencias de estos dos procesos, reconocibles en distintas regiones francesas y, especialmente, en las historias de Inglaterra y Francia, se manifestaron, incluso, en el campo ideológico, ya que, en el primer caso y en lo que se refiere a las regiones francesas, la aceptación de las ideas republicanas fue fácil, mientras que, en el segundo, el rechazo del republicanismo y el apoyo a la monarquía fueron manifiestos ${ }^{43}$. Por tanto, y esto es lo importante en el orden de la argumentación, la variable de la división social de trabajo parece ser suficiente para explicar la centralización política, pero no puede dar cuenta de la génesis del Estado. Éste

41 Badie, B.; Birnbaum, P., Sociologie de l'État, op. cit., p. 112.

42 Así, Tilly, Ch., La Vandée: Revolution et Contra-Revolution, Fayard, Paris, 1970.

43 Para un desarrollo de esta cuestión, vide Birnbaum, Pierre, La logique de L'État, Fayard, Paris, 1982, pp. 13-37. 
requiere tener en cuenta la otra variable, la del modo específico de desintegración de la sociedad tradicional y su sustitución por la sociedad moderna. Así, BIRnBAum defiende que este planteamiento podría explicar, incluso, los distintos procesos seguidos en Europa occidental y oriental, que dieron lugar a la aparición del Estado en el occidente europeo y a la prolongación del dominio de la aristocracia sobre el campesinado servil en la Europa oriental ${ }^{44}$.

La cuestión argumental y metodológica ahora es saber si el nacimiento del capitalismo, el factor económico, es, también, la causa que está detrás y explica lo que hemos llamado el modo específico de desintegración de la sociedad tradicional y su sustitución por la sociedad moderna y el Estado. La respuesta afirmativa es la tesis de WALLERSTEIN, que defiende que la revolución económica es la causa primera del desarrollo del Estado ${ }^{45}$. El capitalismo se convirtió, a partir del s. XVI, en un sistema económico internacional en el que los Estados fueron la pieza funcional imprescindible para garantizar que el centro (el noroeste de Europa, donde surgieron los Estados) de tal sistema internacional se desarrollase a costa de la explotación de las sociedades periféricas de Europa (Polonia, por ejemplo), condenadas a la agricultura y excluidas tanto del nuevo sistema económico como del sistema estatal. El Estado, en este sentido, sería el organizador de la división social del trabajo y el protector de la nueva economía y de sus élites, tanto en el orden nacional como internacional. Esta interpretación funcionalista del Estado la rechaza BIRNBAUM al analizar las sociedades resistentes a los cambios sociales y a la nueva división del trabajo. En estos casos considera más razonable realizar un análisis del Estado basado en un punto de vista más creativo, es decir, genético que funcional, aunque esto no suponga negar la muy probable relación funcional entre transformación económica y construcción del Estado ${ }^{46}$.

Según lo anterior, el Estado no fue la consecuencia del capitalismo mercantil. En primer lugar, porque existía con anterioridad a las transformaciones (económicas y geopolíticas) que tuvieron lugar en el Renacimiento, como se acaba de decir. En segundo lugar, porque la funcionalidad no cabe identificarla con la causalidad. La probable relación funcional entre nueva economía y Estado no debe ocultar que, ante las crisis de la economía precapitalista, el Estado utilizó sus medios, primeramente, para satisfacer sus intereses políticos: necesidades militares, financiación de la burocracia y dominio o control, al menos, del sistema de producción (pólvora, salitre, administración pública de las minas). En tercer lugar, porque el Estado estuvo más preocupado en proteger la sociedad rural tradicional (evitando los conflictos sociales y el

44 Brenner, R., «Agrarian Class Structure and Economic Development in Pre-Industrial Europe», Past \& Present, No. 70, 1976, especialmente pp. 52-75 (30-75).

45 Wallerstein, I., The Modern World System, Academic Press, New York, 1974.

46 Badie, B.; Birbaum, P., Sociologie de l'État, op. cit., p. 116. Igualmente, vide Etzioni, A., «The Epigenesis of Political Communities at the International Level», op. cit. y ANDERson, P., Lineages of the Absolutist State, New Left Books, London, 1974, especialmente, pp. 15-42 y 397-431. 
hambre y protegiendo la economía agrícola) que en defender los nuevos grupos capitalistas, cosa que se repetiría siglos más tarde, cuando el Estado hizo de la aristocracia la beneficiada de las nuevas estructuras económicas. El Estado era, más bien, el 'actor' dedicado a neutralizar los cambios brutales que traía consigo la nueva economía ${ }^{47}$.

Como conclusión provisional, se reconoce la tesis común de la relación (causal) entre la división social del trabajo y la creación de un centro político (no Estado) y, asimismo, la importancia del factor económico en esta relación. Pero la afirmación del marxismo clásico de que es este factor económico el que de manera inevitable produce una centralización completa, es decir, el Estado, no estaría fundamentada, ya que parte de los supuestos de que sólo la economía determina la división del trabajo y que la sociedad no puede funcionar sin Estado, sin tener en cuenta otros factores que influyen en la división social del trabajo: cultura, resistencia al cambio, inercia social, tensiones sociales y cuantos factores el funcionalismo da como causa de la misma.

\subsection{El peso de la estructura social}

Si, como se ha expuesto, el Estado surge como respuesta a las resistencias de las sociedades tradicionales a los cambios sociales, es metodológicamente imprescindible analizar lo que es más esencial a tales sociedades, el feudalismo. De este modo, el feudalismo se convierte en una variable esencial de la explicación del origen histórico del Estado ${ }^{48}$.

En sociedades de economía herméticamente cerrada el sistema feudal podía ser un instrumento de estabilidad, pero no en otras circunstancias, ya que el feudalismo, fuera de su ámbito histórico y social, es portador de una dinámica autodestructiva, que le lleva en último término a la monopolización del poder político, todo lo contrario de la poliarquía medieval. Esta dinámica se debía la confusión de roles (político, social y económico) en el señorío y a la lógica utilización de la fuerza para defender y aumentar su valor y extensión a costa de otro u otros señoríos. De ahí surge el enfrentamiento generalizado que acaba, al final, por crear pocos y grandes señoríos, como ocurrió en Francia, dando lugar a unos sistemas políticos que, por su centralización y extensión, se pueden considerar previos a la creación del Estado nacional ${ }^{49}$. A esta dinámica interna hay que añadir otros factores relacionados, también, con el feudalismo como

47 Incluso Wallerstein (The Modern World System, op. cit.) admitiría que el establecimiento del absolutismo monárquico en Francia se debió más a la necesidad de conciliar el capitalismo mercantil con la economía rural de muchas regiones francesas que al mero hecho del capitalismo.

48 Éste es, igualmente, el punto de partida de Perry Anderson (Anderson, P., Passages From Antiquity to Feudalism, New Left Books, London, 1974 y ANDERson, P., Lineages of the Absolutist State, op. cit.) o de Norbert Elias (Elias, N., La Dynamique de l'Occident, CalmannLévy, 1975, reimpresión 2003, traduction de P. Kamnitzer).

49 Badie, B. ; Birnbaum, P., «Sociologie de l’Etat revisitée», op. cit., p. 190. 
son los cambios militares que redujeron el peso de la aristocracia feudal en el ejército al incorporar personas provenientes de otras clases sociales - para atender nuevos sistemas de guerra- y la progresiva desintegración del feudalismo por el debilitamiento de los lazos entre señor y campesinos y la oposición de la burguesía a los señores feudales, todo ello consecuencia de la economía monetaria. En las sociedades fuertemente feudalizadas no hubo flexibilidad para adaptar ni la estructura social ni la estructura política (ya centralizada en sociedades de feudalismo débil) más que a través de sistemas políticos autónomos, diferenciados y fuertemente institucionalizados (burocratizados) capaces de superar las deficiencias políticas previas y la oposición de los feudales a perder su poder político ${ }^{50}$.

Por otra parte, no hay que olvidar el papel fundamental jugado por la ciudad y, dentro de ella, por la burguesía urbana, fuera del caso de ciudades como las italianas e inglesas, las primeras, ligadas a la aristocracia urbana y las segundas, mucho más dependientes del poder real. Las ciudades se desarrollaron, en general, de manera autónoma y al margen del control señorial y contribuyeron a la construcción del Estado, en primer lugar, impidiendo que los señores feudales reimpusieran en la Europa occidental la institución de la servidumbre al campesinado al estilo de lo ocurrido en la parte oriental y, en segundo lugar, proponiendo frente al modelo de sociedad civil feudal un sistema estatal de control de las ciudades, de su policía, tribunales y finanzas y de organización de la industria y el comercio. No obstante esta pérdida o marginación de la nobleza del poder político, el Estado protegió los privilegios tanto sociales como económicos de la misma en materias tan sensibles como el reconocimiento de la propiedad privada, el sometimiento del campesinado y la exclusión de aquella del pago de impuestos. Y ante la tesis clásica, que ve en el Estado absolutista al instrumento de la aristocracia, BADIE y BIRNBAum defienden que el Estado absolutista tuvo, más bien, la necesidad de componérselas con una sociedad civil ampliamente dominada por la aristocracia, cuya consecuencia fue el mantenimiento, a pesar del intervencionismo social y económico del Estado, de la dominación socio-económica de la nobleza, que, también, favorecía al propio poder estatal. Evidentemente, esto suponía una limitación del desarrollo de la economía liberal y un retraso de la industrialización ${ }^{51}$.

En conclusión, el Estado es, antes que nada «la versión post-feudal de un proceso universal de centralización de las estructuras políticas ${ }^{52}$. Por el contrario, en Inglaterra un feudalismo más débil y directamente centralizado en la institución real, más preocupado por controlar el poder del rey que en independizarse de él, y unos hábitos políticos muy antiguos de representación y de equilibrio entre el autogobierno y el reconocimiento universal del rey y de su poder centralizado hicieron posible que la mayor centralización que exigían

50 Badie, B.; Birnbaum, P., Sociologie de l'État, op. cit., pp. 133-135.

$51 \quad$ Ibídem, p. 136.

52 Ibidem, pp. 138-139. 
los cambios económicos del siglo XV-Xvi pudiera realizarse, sin necesidad de recurrir a una centralización autoritaria y burocrática, a través de un tipo de sociedad civil que no había conocido ni la rigidez ni la atomizada poliarquía medieval continental. Es de destacar que, no obstante la diferencia entre ambos sistemas y sus consecuencias, en los dos existió la institución del parlamento. Se trata de una institución netamente europea, que posiblemente explique que el Estado, fuerte o débil, no ha podido ser considerado de forma permanente como un déspota ${ }^{53}$.

\subsection{El papel de la cultura}

El tercer elemento es la cultura propia del momento, el Renacimiento europeo, a la que se debió el papel de control y de materialización del proceso de creación del Estado. Es decir, entre las distintas alternativas que había para solucionar las crisis de las sociedades tradicionales, la del Estado era inseparable de la cultura europea occidental. Su aportación se concreta en el principio de que la mejor manera de solucionar determinados conflictos sociales consiste en la disociación y autonomización de lo político. Los tres elementos elementos que integran esta cultura propia europea son: el cristinianismo, la familia nuclear y el Derecho romano.

Así, en primer lugar, el elemento más importante de esta 'disociación' es el relativo a la separación entre lo político y lo religioso, donde el cristianismo, después el catolicismo, ha jugado el papel más fundamental ${ }^{54}$. La lucha por la autonomía del poder espiritual, la organización centralizada, jerarquizada y burocrática de la Iglesia más la doctrina de la soberanía papal crearon la imagen que se aplicará en la 'invención' del Estado como nuevo sistema político. El Estado es la reacción a una Iglesia autónoma y auto-organizada. Es «el resultado necesario de la plena disociación del sistema político frente al sistema cultural y religioso ${ }^{55}$. Tal resultado, el de un Estado autónomo, especializado y distinto de la sociedad civil, es evangélico y parte de la teología católica ${ }^{56}$. No se puede decir lo mismo de todas las confesiones cristianas que, según casos, circunstancias y desarrollos teológicos, han aceptado o defendido la sumisión al poder político (Iglesia ortodoxa), la superioridad de lo religioso sobre lo político (puritanismo), la indisociabilidad de ambos sistemas (anglicanismo) o el debilitamiento del Estado sin la oposición de una burocracia religiosa (Reforma, en general).

La misma lógica de disociación que existió entre el poder religioso y el poder político se produjo entre el poder político y la estructura familiar, ya que

53 En este sentido, vide Schulze, H., Estado y Nación en Europa, op. cit., p. 26.

54 Sobre esta cuestión, vide, inter alia Beobide EzPeleta, I. M.; Gordillo Pérez, L. I., La naturaleza del Estado. Origen, tipología y lógica de actuación política y social, op. cit., pp. 2022 y $40-45$.

55 Badie, B.; Birnbaum, P., Sociologie de l'État, op. cit., p. 145.

56 Badie, B.; Birnbaum, P., «Sociologie de l’Etat revisitée», op. cit., p. 190. 
la familia nuclear occidental de la Edad Media carecía de funciones políticas, que sí tenían otros tipos de familia como la tribal o, incluso, la romana (del Imperio romano), en la que el paterfamilias disponía de facultades penales sobre los miembros de su familia. La concentración del poder político por parte de los reyes al crear el Estado encontró una feroz resistencia en la nobleza y en la Iglesia, ya que eran ellas las que serían desposeídas del poder político, pero, por el contrario, no encontró ninguna oposición en la familia nuclear, ya que no perdía nada de naturaleza política. De este modo, la sociedad medieval estaba mejor preparada que otras sociedades a aceptar las características del Estado: la centralización y la monopolización del poder político ${ }^{57}$.

Finalmente, la construcción teórica y práctica (en buena medida jurídica) del Estado encuentra en la cultura jurídica europea de tradición romanista la disociación de categorías (contrato, interés público) e instituciones (privadas y públicas), que permiten concebir la justificación de su existencia y de su legitimidad como sistema autónomo, además de la elaboración del derecho público de la soberanía. No sólo esto, sino que el Derecho romano da lugar a la creación de los profesionales del Derecho, los legistas, que pueden ser considerados como los primeros burócratas del Estado, tal como ocurrió en la Francia de Felipe el Hermoso. Gracias a su formación jurídica ejercían funciones y poderes propios del Estado y «distintos, además, de aquellos que derivaban de su posición en la sociedad civil» ${ }^{58}$. Hay una concatenación de datos en los países romanistas (Francia, por ejemplo) entre la recuperación del Código Justiniano, las primeras glosas, los legistas y la formación inicial del Estado. Hay que tener en cuenta, además, la cultura jurídica consustancial al Derecho romano y la cultura individualista de la Europa occidental, herencia de la interpretación cristiana del ser humano como ser moral responsable, ya que el surgimiento de una economía autónoma, tanto en lo que se refiere al pensamiento económico como a la acción económica, fue consecuencia de esta cultura, que en último término puede definirse como individualización de las relaciones sociales y de las relaciones del hombre con las cosas ${ }^{59}$.

El resultado de este modelo cultural es que se acaba convirtiendo a la economía en una categoría autónoma y superior a todas las demás. Siendo esto así, el Estado no fue la consecuencia evolutiva y lógica de una fórmula universal de cambio social, sino que respondía a una cultura particular, que permitió solucionar las graves crisis sociales del final de la Edad Media ${ }^{60}$.

57 Beobide Ezpeleta, I. M.; Gordillo Pérez, L. I., La naturaleza del Estado. Origen, tipología y lógica de actuación política y social, op. cit., pp. 39-40.

58 Badie, B.; Birnbaum, P., Sociologie de l'État, op. cit., p. 151.

59 Beobide EzPeleta, I. M.; Gordillo Pérez, L. I., La naturaleza del Estado. Origen, tipología y lógica de actuación política y social, op. cit., pp. 22-24.

60 Badie, B.; Birnbaum, P., Sociologie de l'État, op. cit., p. 143-153. 


\section{El ESTADO: UNA CREACIÓN ORIGINAL E IMPUESTA}

El resultado en este proceso histórico, que va desde el final de la Edad Media hasta el Renacimiento, según el análisis de los factores del capitalismo, estructura social y cultura europea occidental, fue la invención del Estado, uno de los sistemas políticos en los que cabía pensar como alternativas a la forma política medieval ya en su ocaso y que sólo se produjo en aquellos países europeos definidos por las características examinadas. El Estado, cuya naturaleza se capta más por sus estrategias que por las teorizaciones de los autores, no se debió a la iniciativa de entes colectivos (burguesía o aristocracia) para satisfacer sus necesidades (tesis de Anderson), sino al fracaso de los sistemas comunitarios y asociativos medievales de protección de los individuos ${ }^{61}$.

Esta invención (el Estado) consistió en la creación de «un sistema de roles institucionalizados funcionando de manera permanente, poseedor legítimo del uso de la fuerza, controlador del territorio sobre el que ejerce su soberanía, ejerciendo el poder de tutela, incluso, sobre la más lejana de las provincias, defensor de sus fronteras y máquina político-administrativa puesta en práctica por funcionarios reclutados de manera impersonal según criterios meritocráticos» ${ }^{62}$.

Las características de este sistema son: universalidad, territorialidad, soberanía, institucionalización, autonomía, diferenciación, centralización, jerarquía, racionalidad, burocracia, ejército permanente público, hacienda pública, justicia pública y monopolio del Derecho, de la fuerza y del poder político. El Estado se entiende como la realización de la Razón libre de toda idea particular, que acaba con todas las formas privadas de poder, con el patrimonialismo y la dominación carismática o de grupo, sea la nobleza, los mercaderes o los guerreros. Este Estado diferenciado incluye la ruptura o distanciamiento con la clase económica dominante, su propio sistema impositivo de financiación, el control de las fuerzas armadas, la ruptura real con las Iglesias y la marginación de los partidos políticos salvo para ser instrumentos para la representación democrática, todo ello para garantizar la autonomía de las élites propias del Estado. El Estado así concebido no es favorable para la creación de una democracia pluralista y liberal, porque tiende a reducir la autonomía de los actores sociales y de las estructuras intermedias, como, por ejemplo, los sindicatos o los grupos de presión, considerados como defensores de intereses particulares. Cuanto mayor es la diferenciación e institucionalización del Estado, menor es la autonomía de sus actores. Lo mismo ocurre, aunque en menor medida, con los actores ajenos al Estado, porque la cultura transmitida por el Estado

61 Badie, B.; Birnbaum, P., «Sociologie de l’Etat revisitée», op. cit., p. 190.

62 Badie, B.; Birnbaum, P., Sociologie de l'État, op. cit., p. 173 y Birnbaum, P., «La fin de l'État ?», op. cit., p. 981. Aunque criticado por BirnBaum, vide igualmente, Tilly, Ch., La Vandée: Revolution et Contra-Revolution, op. cit., pp. 303-304 y 309. 
condiciona su comportamiento de una manera más fuerte que en una sociedad democrática ${ }^{63}$.

Esta gran institucionalización tiene consecuencias importantes en el orden de la representación, ya que es la Administración del Estado, representante y gestora del interés general, y no el Parlamento, el verdadero órgano representativo de la sociedad. En su virtud, la Administración interviene en la sociedad civil y la controla, aporta sus funcionarios a los distintos gobiernos del Estado, los presenta como candidatos bien sea al Parlamento o bien a las grandes alcaldías, los nombra directores de las corporaciones de servicio público, bancos nacionalizados, firmas semipúblicas e, incluso, los cede para trabajar en las grandes firmas privadas. Todo esto indica que el fin del Estado parece ser el de civilizar a toda la sociedad ${ }^{64}$.

Además de Francia, ejemplo paradigmático para BIRnBAum de Estado fuerte, diferenciado e institucionalizado, otros países que han seguido una trayectoria semejante a la de Francia, aunque con muy notables diferencias, según los casos, en sus procesos y en sus resultados, han sido Prusia (y, por extensión, Alemania), Italia y España. El caso de Rusia, a pesar de la creación de un centro político, obedece más al modelo de creación de un Imperio ${ }^{65}$.

Ahora bien, no todo sistema político posterior a la Edad Media tuvo las características políticas de un Estado, que en esencia es el modelo que permitió el gobierno de la sociedad civil a través del propio Estado, sino que hubo otro modelo, que responde a factores distintos y que permitió el gobierno por y a través de la sociedad civil, cuyo ejemplo más logrado es el de Gran Bretaña.

El abandono progresivo de las estructuras medievales tuvo en el caso de la actual Gran Bretaña el efecto de acentuar el control del parlamento sobre el emergente centro de poder que se solapaba con las estructuras medievales, que eran de signo eminentemente local. Ello acabará provocando la consagración del principio parlamentario que impedirá la creación de la monarquía absoluta o el desarrollo de un poder ejecutivo muy fuerte.

Supuesto este sistema político y la cohesión social inglesa, se entiende que todavía en el siglo XVII apenas existiera burocracia central, ni un Derecho o unos tribunales administrativos o el escaso reconocimiento de prerrogativas especiales al poder público. Aunque Inglaterra no era ajena al Derecho romano, su tradición se basaba en el derecho común, basado en normas procedimentales, especialmente, el precedente, y sus tribunales los formaban los ciudadanos ordinarios. Las razones de por qué Inglaterra no desarrolló las características del Estado que describe BiRnBAum (tomando como parámetro de comparación a Francia) están, en primer lugar, en que no existieron motivos que exigiesen la diferenciación del sistema político con respecto a la sociedad, ya que

63 Birnbaum, P, «État»; Borlandi, M.; Aulagne-Drivry, F., Dictionnaire de la pensée sociologique, PUF, Paris, 2005, pp. 248-250.

${ }^{64}$ Badie, B.; Birnbaum, P., Sociologie de l'État, op. cit., pp. 173-188 y Birnbaum, Pierre, La logique de L'État, op. cit., pp. 193-213.

65 Badie, B.; Birnbaum, P., Sociologie de l'État, op. cit., pp. 154-160, 173 y 188-195. 
el gobierno estaba en manos de una clase social que aunaba a la nobleza (con muchos menos privilegios que en el continente y sin reparos en participar en el mundo de los negocios), a la burguesía y a la nobleza local. Es decir, la no diferenciación era funcional. En segundo lugar, por la alta movilidad social entre políticos y hombres de negocios y por las instituciones de gobierno representativo propias del sistema inglés. Además, el rápido crecimiento del capitalismo y del mercado evitó los efectos estatales del retraso económico continental. Es decir, el predominio de gobierno en el caso inglés estaba en la sociedad civil y en el mercado, pero no en un Estado que ciertamente no existía.

El resultado de todo lo anterior en lo que se refiere al binomio SociedadEstado es que en el caso de Gran Bretaña la autoorganización de la sociedad civil ha hecho innecesaria la creación de un Estado fuerte, poderoso, altamente institucionalizado, diferente, separado y autónomo de la sociedad civil, que a través de su gran burocracia dominara a la sociedad. En lugar del Estado ha sido suficiente un centro político (centralización política), cuyas funciones no han consistido en imponerse sobre la sociedad civil, sino en coordinar las actividades sociales y políticas ${ }^{66}$. Así pues, ha sido Gran Bretaña la que ha encarnado el prototipo de sistema político centralizado (en contraposición al «Estado fuerte»), pero otros países como Estados Unidos de América, Holanda o Suiza han seguido sus pasos, aunque con algunas diferencias producto de las diferencias culturales y religiosas fundamentalmente ${ }^{67}$.

En el caso americano (Birnbaum, 1982: 55), un país sin pasado feudal, con una sociedad creada por «autorregulación», a la vez democrática y elitista, sin una autoridad centralizada fuerte (en un principio, al menos), con la soberanía dividida y el poder repartido, con un individualismo extremo, apoyado, además, por el puritanismo protestante, el Estado fuerte no tenía cabida por intruso, por déspota y por contrario al principio de legitimidad americano basado en la libertad, la igualdad (únicamente de oportunidades, no de resultados), la sobrevivencia de los mejores y el mito del héroe emprendedor, es decir, el mito de la legitimidad de las élites, principalmente, la económica, para dirigir el país. En el caso de Suiza, un país de democracia consociacional o consensual (no hay que olvidar las instituciones de democracia directa y las decisiones tomadas por mayorías) y de lealtades periféricas, son los distintos grupos los que garantizan la cohesión social; es decir, ni la sociedad ni el Estado son los garantes de tal cohesión. De gran parecido con el caso de Gran Bretaña, no puede, sin embargo, decirse que disponga de una centralización política. Más bien carece de esta condición, así como también de un Estado completo. De ser en la historia una Confederación pluralista desde su creación en el siglo XIII hasta la Revolución francesa, fueron ésta y el liberalismo del siglo XIx los factores que impulsaron la creación de una unidad y centralización políticas y, también, una unidad económica que se expresaron en la Constitución federal de 1848. Fue la

66 Birnbaum, P., La logique de L'État, op. cit., pp. 14-15 y 21.

67 Badie, B.; Birnbaum, P., Sociologie de l'État, op. cit., pp. 196-203. 
necesidad de salvar la Confederación lo que impulsó la unidad económica del mercado y la unidad de un sistema político, que no rompió con el pluralismo de los grupos sociales y no fortaleció el poder central. La burocracia central es reducida y básicamente funciona el sistema con una burocracia periférica, con funcionarios que carecen de estado legal, nombrados cada cuatro años, que no están diferenciados de la sociedad civil, seleccionados por méritos, pero también por criterios lingüísticos, religiosos y culturales. Mientras que los hombres de negocios y directores del sector privado abundan en el Parlamento, apenas existe representación de la Administración en el Parlamento ${ }^{68}$.

En todos estos casos de Estado débil nos encontramos ante países con una democracia más abierta al pluralismo, de cultura protestante, muy individualistas, con sistemas descentralizados y hasta federales, que dan a los grupos locales una autonomía política, además, de social y cultural. Otras sociedades, protestantes o católicas, también han intentado, posteriormente, evitar la concentración de poder en el Estado y desarrollar sociedades de mayor pluralismo. Se puede decir que los modelos siguen en pie, el Estado fuerte y el Estado débil, en sociedades definidas por la misma cultura y la misma vida social.

\section{LOS RETOS DEL ESTADo CONTEMPORÁNeo}

El Estado, según BirnBaum, se encuentra amenazado por distintos procesos de diferenciación, que pueden afectar a su institucionalización, ya sea completa (el Estado fuerte) o incompleta (otros tipos de Estado o no-Estados, pero que copian algún elemento del Estado $)^{69}$. Podríamos estar asistiendo a la paradoja de un Estado dominante que, a la vez, camina hacia su fin. Estas amenazas podrían agruparse en dos grandes categorías: las de tipo endógeno y las que son producto de llamada globalización.

\subsection{Las amenazas endógenas}

En cuanto a esta primera categoría de amenazas, cabe aseverar, en primer lugar, que cualquier forma de democracia participativa es un riesgo para el Estado porque pone en cuestión su diferenciación. Esto ocurre, por ejemplo, con la pretensión de convertir el espacio público en el espacio de los ciudadanos y no del Estado, con la identificación de la ciudadanía con la participación, o con el desarrollo de la vida asociativa, de la democracia local y de movimientos autogestionarios ${ }^{70}$.

68 Badie, B.; Birnbaum, P., Sociologie de l'État, op. cit., pp. 203-217.

69 Vide los problemas que plantea el autor en Birnbaum, P., La logique de L'État, op. cit., pp. 215-224 y 225-234.

70 Birnbaum, Pierre, «La fin de l'État? », op. cit., pp. 982-983 y Birnbaum, P, «État», op. cit., p. 250. 
En segundo lugar, muchas teorías, desde los análisis de Tocoueville hasta Nozick o TAYLOR, ponen en cuestión la diferenciación del Estado, bien al contraponer la fortaleza del Estado con la debilidad de la democracia o, al revés, al presentar la democracia representativa como opuesta a la diferenciación estatal, bien al defender una concepción atomística de la sociedad, en la que el interés individual es el único criterio frente al Estado gestor del interés general. La perspectiva libertaria busca democracias sin Estado y sin Estado de bienestar, sea fuerte o débil, democracias basadas en el mercado, cuyo objetivo expreso es la diferenciación del Estado, o basadas en la formación de pequeñas comunidades. BIRnBaum piensa que no será fácil que este individualismo pueda afectar al Estado plenamente diferenciado y celoso de guardar su «lógica»; más bien, este individualismo encaja en la «lógica» del Estado débil ${ }^{71}$.

En tercer lugar, en el Estado no diferenciado (Gran Bretaña o EE UU), lugar donde, tal como ya se ha expuesto, tienen representación los diversos intereses sociales a través de grupos de presión y asociaciones, juegan un papel importante las numerosas élites periféricas y los representantes de intereses socioeconómicos. Es el ámbito ideal para el desarrollo de un corporativismo selectivo (y su correspondiente control de sus adheridos), para la conversión de ciertos grupos de presión en instituciones gobernantes, para que instituciones privadas realicen funciones administrativas y, en definitiva, para que funcionarios y representantes negocien las decisiones a tomar ${ }^{72}$.

La crisis del Estado se agrava, además, por otros problemas, que dificultan su función de gobernabilidad. Entre estos destacan la «sobrecarga» a la que están sometidos por un exceso de demandas (salarios, salud, educación...) cuya fuerza y número se multiplican por efecto de la propia extensión de la democracia y cuyo incumplimiento pone en peligro la lealtad ciudadana o incita a políticas clientelares. Esta sobrecarga, bien obedezca a cuestiones económicas estructurales o a dificultades técnicas, se ha tratado de superar por medio de mecanismos de representación, a cuya cabeza está el corporativismo, que, sea cual sea su tipo, es un grave inconveniente de la diferenciación del Estado ${ }^{73}$.

Un tal corporativismo negociador de políticas económicas particulares («específicas»), tan propio de una sociedad con Estado débil, es incompatible con un Estado altamente institucionalizado y diferenciado, como lo son los grupos de presión o la representación de intereses privados en el Estado. Sin embargo, el Estado fuerte también está amenazado de perder parte de su diferenciación

71 Para una revisión de Tocoueville, su De la démocratie en Amérique (1835/1840) y su pensamiento en general, vide Velasco CRIADO, D., «Tocqueville (1805-1859), dos siglos después», Estudios de Deusto, Vol. 53/1, 2005, pp. 183-250. Para un breve estudio crítico de la obra de referencia Nozick, R., Anarchy, State, and Utopia, Basic Books, New York, 1974, vide Rothbard, M. N., "Robert Nozick and the Immaculate Conception of the State», Journal of Libertarian Studies, Vol. 1/1, 1977, pp. 45-57. Igualmente, vide TAYLoR, Ch., Philosophical Arguments, Harvard University Press, Cambridge, 1995 (reimpresión 1997), especialmente, pp. 127-144 y 181-203.

72 Birnbaum, Pierre, «La fin de l’État? », op. cit., pp. 983-986.

73 Badie, B.; Birnbaum, P., «Sociologie de l'Etat revisitée», op. cit., pp. 195-196. 
al haber penetrado en sus estructuras muchas de las personas y de los elementos compatibles con el Estado débil: comerciantes, notarios, sindicalistas, dirigentes, hombres de negocios y asociaciones. La representación («reflejo») social de la nación va penetrando en el Estado con la idea de pretender una democracia fuerte y de realizar una especie de «sistema de despojos». A estos hechos acompaña un discurso político e intelectual, que se resume en que para cambiar la vida hay que cambiar el Estado y dar preeminencia a la sociedad civil sobre el Estado. Una de sus realizaciones sería la promoción de los notables locales a costa de los agentes públicos del Estado central, que obliga a la administración del Estado, para poder funcionar, a crear lazos privilegiados con los representantes de los intereses locales. Igualmente, se están produciendo prácticas de tipo incrementalista y clientelar, que marcan la tendencia a la desdiferenciación del Estado. Birnbaum inscribe todas estas políticas en un socialismo autogobernante de vuelta hacia la sociedad ${ }^{74}$.

Estas tendencias a la privatización del sector público, que son contrarias a la lógica de un Estado fuerte, parece que amenazan con más ímpetu a las instituciones del Estado débil como lo prueban las nuevas normativas de regulación por el mercado o las desnacionalizaciones ${ }^{75}$. El caso de Francia, un Estado fuerte, nos muestra que los movimientos contrarios a la creación de la diferenciación e institucionalización del Estado han sido muchos (la contrarrevolución de la Vendée, las revoluciones del siglo XIX, la Comuna de París, el movimiento anarco-sindicalista, mayo del 68) y su acción colectiva ha sido tanto más antiestatal cuanto más fuerza tenía el Estado. Sin embargo, de todos estos enfrentamientos el Estado francés habría salido más fuerte y más legitimado, lo que le ha permitido controlar lo mismo a la extrema derecha que a la izquierda durante el siglo $\mathrm{xx}^{76}$.

Cada lógica estatal se enfrenta a su manera con estos problemas lo mismo que con los problemas socioeconómicos o las relaciones industriales de manera que cabe decir que los movimientos antiestatales contra el Estado fuerte y democrático fortalecen aún más al Estado. Éste no cede más que ante lo excepcional o extraordinario. En el caso del Estado débil y democrático hay poca movilización extrema y no suele ir contra el Estado; el enfrentamiento entre los actores sociales se ventila dentro de la sociedad civil, incluso con huelgas duras y largas, pero no politizadas, todo lo contrario que en un Estado fuerte, donde cada parte busca al Estado para ponerlo de su lado. Y en el caso de un Estado no suficientemente fuerte y de débil democracia, las movilizaciones antiestatales destruyen el Estado, como ocurrió con el movimiento nazi en Alemania, donde la diferenciación desaparece cuando el poder se da a un hombre a la vez que se produce el enfrentamiento entre los distintos grupos ${ }^{77}$.

74 Birnbaum, P., «La fin de l’État?», op. cit., pp. 986-988.

75 Birnbaum, P., «Etat», op. cit., p. 251.

76 «Esta fuerza del Estado no cede más que ante lo excepcional, es decir, la derrota militar y la ocupación», Badie, B.; Birnbaum, P., «Sociologie de l’Etat revisitée», op. cit., p. 196.

77 Ibídem, pp. 196-197. 
Estas diferentes respuestas estatales obedecen, también, a actitudes distintas de los movimientos sociales, los cuales se adaptan a la lógica de cada Estado. Esto ocurre, sin ir más lejos, con los movimientos antinucleares o con los movimientos estudiantiles. En los Estados fuertes el movimiento social va directamente a desestabilizar al Estado, mientras que en el caso contrario tiene un carácter más local o descentralizado. Estos movimientos sociales en Francia («indiferente a las demandas de los nuevos movimientos sociales y seguro de su propia racionalidad») suelen realizar acciones duras, violentas, centralizadas según el modelo estatal o, incluso, cuasi insurreccionales, mientras que en países como Suiza o Estados Unidos, la descentralización y fragmentación políticas estructurales y de los mismos partidos políticos permite más fácilmente el diálogo, la toma en consideración de las demandas y la negociación ${ }^{78}$.

\subsection{Las amenazas de la era de la globalización}

Según Birnbaum, el Estado fuerte en la actualidad se enfrenta con otros movimientos producto de la era de la globalización que lo destruyen o quieren destruirlo: el fundamentalismo religioso, la inmigración, el desorden internacional y las guerras.

El fundamentalismo religioso se subleva contra la estructura estatal de los países a los que se ha importado el tipo de Estado fuerte europeo como son, por ejemplo, Turquía o Túnez. Turquía ha querido construir un Estado fuerte y diferenciado (el Estado kemalista podría considerarse un Estado jacobino) con todas las connotaciones propias de tal tipo de Estado (negación de los particularismos, laico, burocrático, secularizado) e imponerse sobre la sociedad civil musulmana, cuya religión rechaza la separación de la religión y la política y el resto de características propias del Estado. El mismo problema se vive en Túnez por obra del islamismo. Y, en cierto modo, un problema semejante se plantearía en Francia con la creciente comunidad musulmana, que pone en cuestión el concepto de ciudadanía entendida como única pertenencia al Estado y que da lugar a que se defienda por parte de algunos la necesidad de separar ciudadanía y nacionalidad. La primera daría derecho, por ejemplo, al voto y la segunda haría del musulmán un extranjero.

Francia, prototipo de Estado fuerte, sigue ante la inmigración en sus tesis de imponer sus valores universales a todos los ciudadanos, a través de la escuela y el ejército, y de rechazar el ejercicio público de sus valores y culturas. Y, aunque el acceso de los inmigrantes a la ciudadanía francesa es fácil, no se permite ninguna organización de tipo étnico. La persistencia de la inmigración en mantener sus valores colectivos, las reacciones xenófobas (organizadas a nivel nacional) y antiestatales por su generosidad con los extranjeros y la movilización de la extrema derecha son factores añadidos a la crisis del Estado por poner en cuestión la diferenciación. Pero lo que ocurre en Francia con la

${ }^{78} \quad$ Ibidem, p. 197. 
inmigración no es lo mismo que lo ocurre en Alemania o Gran Bretaña. Para los inmigrantes a Alemania, básicamente una comunidad cultural, les es muy difícil tener acceso a la nacionalidad en cualquiera de sus generaciones. Por otra parte, las actitudes xenófobas no obedecen a una movilización organizada nacionalmente. El problema contra la legitimidad del Estado (crisis del Estado) es más bien de tipo moral. El caso de Gran Bretaña con la inmigración es distinto por su origen político (Commonwealth), por disponer de nacionalidad y ciudadanía británicas, por su integración en la estructura institucional del Estado y por la expresión prácticamente libre en el espacio público de sus culturas, todo lo cual no evita una xenofobia tan grande como en otros países, pero ésta, al no organizarse a nivel estatal más que raramente, no plantea una amenaza seria contra el Estado, aunque le ha obligado a cambios profundos en la organización de su sistema de seguridad interior ${ }^{79}$.

El caso es que tanto en los Estados débiles como fuertes existe el riesgo de una ciudadanía multicultural, que debilita la pertenencia única al Estado. Por otra parte, comunidades étnicas muy cerradas sobre sí mismas ponen en cuestión la coherencia del espacio público al exigir que sus culturas respectivas superen el nivel particular para incorporarse al espacio público ${ }^{80}$.

En cuanto al desorden internacional, BiRnBAUm nos recuerda cómo en el último cuarto del siglo xx diversos factores han puesto en cuestión el orden internacional, que desde el siglo XvII se fue creando a imagen y semejanza del Estado y ha funcionado como una comunidad de Estados nacionales. Tales factores son el fracaso de la universalización del Estado, el desarrollo de las relaciones transnacionales y la crisis de las formas de regulación interestatal. La universalización del Estado con la descolonización no ha pasado de ser una apariencia de desarrollo político, ya que el producto importado, el Estado, no respondía ni a las necesidades ni a las culturas propias de los países independizados que, a la vez que pretendían imponer el sistema estatal, desarrollaban políticas comunitarias basadas en símbolos y sentidos propios de su cultura endógena. Esta contradicción ni ha permitido la instalación de los elementos del Estado ni la creación de alternativas. El resultado ha sido el populismo, autoritarismo y manipulación de la cultura tradicional, que tiene poco que ver con el desarrollo político y más con la creación de una oposición entre el modelo importado y las estructuras sociales. Datos de este fracaso se encuentran en todo el mundo a donde se ha exportado el modelo del Estado, desde América latina hasta África, con la descomposición de las instituciones políticas y administrativas, la profusión del populismo y los movimientos revivalistas, que apenas dejan lugar al espacio público diferenciado. La consecuencia es la banalización del sistema político estatal internacional, uno de los posibles sistemas de orden. Esta crisis internacional, fruto de la fracasada universalización del

79 Birnbaum, Pierre, «La fin de l'État?», op. cit., pp. 990-992; Badie, B.; Birnbaum, P., «Sociologie de l'Etat revisitée», op. cit., pp. 197-187 ; BirnBaum, P., La logique de L'État, op. cit., pp. 142-146.

80 Birnbaum, P., «Etat», op. cit., p. 251. 
Estado, afecta a la legitimación del Estado, basada precisamente en la universalidad y en el dominio de la función político-diplomática a efectos de orden interior. Y esto está ocurriendo, incluso, en las sociedades europeas occidentales. La proliferación de relaciones transnacionales (flujos económicos y financieros, culturales y religiosos, intensificación de la información y de la comunicación) al margen de los Estados es un fenómeno no sólo propio de los países del tercer mundo, sino también de las sociedades desarrolladas, que tiende a sustituir la ciudadanía por estas nuevas formas de solidaridad. Los mismos Estados se ven en graves dificultades de controlar la inmigración, relativizando el concepto de frontera y territorio. En definitiva, la individualización de las relaciones internacionales afecta al Estado, ya que pone en cuestión la soberanía estatal de la política exterior. La lógica del Estado pasa, así, a coexistir con la autonomía de estos nuevos actores internacionales a los que no puede controlar y con los que se ve obligado a negociar, a pesar de negarles su legitimidad. La desestatalización de las relaciones internacionales, que acaba debilitando la relación de ciudadanía, la diseminación de la violencia entre el Estado y los nuevos grupos, que disminuye la eficacia del Estado en el orden internacional, y la desterritorialización, que pone en cuestión el criterio moderno de la necesidad de un territorio como soporte legítimo y funcional de un sistema político, son sus efectos. De este modo, como denuncia Birnbaum, las estrategias hegemónicas más seguras y más eficaces pasan, cada vez menos, por la construcción de una potencia territorial $^{81}$.

La guerra, por su parte, es una amenaza para los Estados fuertes que describe el autor francés. Lo prueban las dos guerras mundiales, que llevaron a Alemania de ser un Estado bajo le hegemonía de una Prusia plenamente burocratizada a ser, tras la primera guerra mundial, la República de Weimar, la república de los partidos y sus clientelas, en un enfrentamiento soterrado entre Estado y República; y, tras la segunda guerra mundial, a ser un federalismo que fortalece a los Länder dotándoles de grandes recursos y de fuertes burocracias. La descentralización provoca la debilidad de los servicios federales y el papel de la segunda cámara del Parlamento debilita aún más la unidad del Estado. Los partidos pasan a ser órganos del Estado y la burocracia, a todos los niveles, se politiza. Todo ello pone en cuestión al Estado. Las guerras también han afectado al Estado francés, pero ello no ha supuesto el fin del Estado, ya que los efectos son menores en un Estado plenamente institucionalizado.

\section{EPílogo}

BIRnBaUm concluye provisionalmente que todo tipo de Estado está amenzado en la actualidad por el asalto de los intereses privados, corporativismos,

81 Badie, B.; Birnbaum, P., «Sociologie de l’Etat revisitée», op. cit., pp. 198-201 y BirNBAUM, P., «Etat», op. cit., p. 251. 
movimientos extremistas, guerras, autogobierno de la sociedad, integración europea (el mercado único), nacionalismos y movimientos transnacionales. Pero el más capaz de resistir estos desafíos es el Estado fuerte, el Estado plenamente diferenciado e institucionalizado ${ }^{82}$.

Anteriormente, en la La logique de L'État y ante la evidencia de la pérdida de autonomía del Estado francés por su dependencia de la clase hegemónica en las relaciones económicas, Birnbaum había escrito que tal dependencia no podía ocultar el «formidable» desarrollo del aparato del Estado y que «el modo particular de construcción del Estado que se ha instaurado no cesa de ejercer su propia lógica».

A pesar de las amenazas que se ciernen sobre el Estado, el autor francés sigue defendiendo que el Estado no ha llegado a su fin. Al contrario, los Estados siguen conservando gran parte de sus prerrogativas; su pérdida de poder frente a elementos internos (corporativismo) o externos (UE, OMC) es más relativa de lo que a veces se concluye y, en todo caso, los Estados muestran siempre su capacidad de adaptación a las nuevas circunstancias, de suerte que por muchas razones la derrota del Estado como fenómeno histórico sería más un mito que una realidad $^{83}$. Así, Touraine confirmaría esta tesis en lo que se refiere a Francia al reconocer que el problema en su país no es el debilitamiento del Estado, sino la dificultad de la sociedad francesa de escapar a los controles asfixiantes del Estado $^{84}$.

Universidad de Deusto

Luis I. Gordillo PÉrez

Facultad de Derecho

Avda. Universidades 24

E48007 - Bilbao (España)

luis@gordillo.eu

[Artículo aprobado para publicación en diciembre de 2015]

82 Birnbaum, P., «La fin de l'État?», op. cit., pp. 992-994.

83 Birnbaum, P., «Etat», op. cit., pp. 251-252.

84 Touraine, A., "Crise de l’État ou crise de la societé française?», Badie, B.; DÉloye, Y. (Dirs.), Le temps de l'État. Melanges en l'honneur de Pierre Birnbaum, Fayard, Paris, 2007, p. 397 (386-397). 